\title{
Xi Jinping's Theoretical Connotation and Practical Path on the Important Exposition of Leading Cadres' Family Style Construction
}

\begin{abstract}
Jia Jing ${ }^{1, a}$
${ }^{1}$ Institute of Marxism, Tianjin Professional College, Tianjin, China

a2275115181@qq.com

ABSTRACT

Since the 18th National Congress of the Communist Party of China,General Secretary Xi Jinping has seized the "critical minority" of leading cadres,standing at the height of seeing Party self-governance exercised fully and with rigor,announced new expositions, new viewpoints and new requirements about the leading cadres' family style construction on several important occasions.He emphasized that leading cadres should fully realize the important position of the construction of family style and grasp the main focus of the construction of family style.At the same time,the paper explore and analyze the practical path to promote the construction of leading cadres' family style. We should make full use of systematic thinking to carrying forward the red family tradition,setting up the positive and negative education model,perfecting the system of internal Party regulations,and,compacting responsibility.
\end{abstract}

Keywords: Xi Jinping, Leading officials, Family style construction

\section{习近平关于领导干部家风建设重要论述的 理论内涵与实践路径}

贾晶

${ }^{1}$ 天津职业大学马克思主义学院, 天津, 中国 a2275115181@qq.com

\section{摘要}

十八大以来, 习近平总书记站在全面从严治党的高度, 紧抓领导干部这一 “关键少数”, 多次在重要场合发表 了关于领导干部家风建设的新论述、新观点、新要求, 着重强调各级领导干部要充分认识到家风建设的重要地 位, 抓住家风建设的主要着力点。同时要运用系统思维, 综合施策, 弘扬红色家风、开展正反教育、健全党纪 党规、从严压实责任等, 努力凝聚多方合力, 打好推进领导干部家风建设的“组合拳”。

关键词: 习近平，领导干部，家风建设

\section{1. 前言}

家齐而后国治。十八大以来，习近平总书记高度 重视领导干部的家风建设问题, 把领导干部家风建设 作为全面从严治党落细、落实的重要举措, 强调要把 领导干部家风建设作为作风建设的题中之义, 各级领 导干部要严管亲属, 过好亲情关, 修好家风建设的“必
修课”，努力实现家风与党风政风的良性互动。

\section{2. 领导干部家风建设的重要地位}

2021 年 1 月 24 日晚，中央纪委 “开年大片”《正 风反腐就在身边》电视专题片播出，其中第四集《严 正家风》讲述了张茂才、向力力、严春风、彭定邦等 被不良家风刮倒的典型案件。广大的领导干部要引以 
为戒, 增强管家治家的政治自觉, 并将其看成一项净 化党内政治生态的基础性工程。

\section{1 锤炼过硬作风的必然要求}

习近平总书记强调: “领导干部的家风, 不是个人 小事、家庭私事, 而是领导干部作风的重要表现” ${ }^{[1]}$ 。 这表明培育优良家风已然成为锤炼过硬作风的必然 要求。领导干部家风建设作为映射其作风是否过硬的 一面镜子, 更能直接反映出领导干部在“八小时之外” 是否依然坚守党性、永葆初心。锤炼领导干部过硬的 作风重在真抓实, 要从家风建设的这一容易被忽视的 细节抓起, 定期检查相关情况, 抓好任务落实。老一 辈革命家一生廉洁为官, 严管子女, 不仅培育了清正 家风, 更树立了领导干部在人民群众心中的光辉形象, 密切了干群党群关系。反观部分家风不正的领导干部, 家庭关系扭曲化, 公权私用, 放任家属狐假虎威, 严 重损害了党和政府在人民心中的形象。对此, 领导干 部一定要有清醒的政治认知, 坚定家风建设的政治自 觉, 主动用优良的家风建设涵养作风建设。

\section{2 推进党风廉政建设的重要抓手}

习近平总书记曾指出: “领导干部的家风, 不仅关 系自己的家庭, 而且关系党风政风” ${ }^{[2]}$ 。领导干部家 风建设与党风廉政建设相互交织, 是推进反腐倡廉的 重要举措。领导干部家风建设背后蕴藏着深刻的政治 逻辑, 即: 家风败坏是领导干部走向腐败之路的主要 推手。从 “严夫人” 要威风, 牵出 “两面人” 的严春 风, 到 “兄弟联手、中饱私囊” 的向力力, 再到 “宠 溺爱子、收钱办事” 的张茂才, 一桩桩家庭成员暗箱 操作捞钱贪财的阵仗, 最终都以 “反面警示性案例” 的悲剧黯然落幕。这些领导干部的腐败机理凸显出家 风败坏是持之以恒推进党风廉政建设的重大威胁。广 大领导干部要充分认识到好的家风, 不仅可以构筑起 拒腐防变的“防护网”, 更是推进党风廉政建设的关键 一环。

\section{3. 习近平领导干部家风建设观的主要着力点}

习近平总书记在十九届中央纪委五次全会的讲 话中指出: “各级领导干部要带头遵守党纪国法, 自觉 反对特权思想、特权现象, 带头廉洁治家, 从严管好 家属子女和身边工作人员。 ${ }^{[3]}$ ” 这一重要论述凸显了 领导干部家风建设的主要着力点, 为领导干部加强家 风建设提供了基本遵循。

\section{1 领导干部家风建设的关键是正确对待权 力}

梳理近年来中央纪委对高官落马事件的通报，不 难发现 “公权私用” 往往与 “家风败坏” 同时出现, 可以说 “领导干部家风不正的本质是对权力的滥用。 [4]” 领导干部作为手握权力的特殊人群, 其权力的适
用不会因为进入家庭生活领域而失去效力, 一旦权力 这把 “双刃剑” 行使不当, 则易出现利用公权力为亲 属牟私利的乱象。领导干部要厘清权力的授受关系, 清醒的认知到权为民所赋, 只能姓公不能姓私, 要胸 怀人民, 敬畏权力, 把好用权 “方向盘”。同时, 要带 头坚决反对特权思想、特权现象。特权思想是滋生家 风不正的 “温床”, 部分领导干部自恃功高, 认为搞点 特权没什么, 其家属便盛气凌人, 以权压人, 在心理 上有一种谜之优越感。例如在微信群要官威的 “严夫 人” 便是特权思想在作崇。特权现象损害社会公平正 义, 部分领导干部滥用手中公权力, 在政治上任人唯 亲、经济上 “前门当官, 后门开店”, 伙同亲属捞钱谋 私、生活上公车私用, 公款吃喝等等; 这些都是人民 群众最为痛恨的现象, 最伤党群干群关系。领导干部 要以铁面无私的姿态铲除滋生特权思想土壤, 家人一 旦出现不良苗头, 就要及时纠正, 批评教育, 严禁亲 属假借公权力的光环耀武扬威。

\section{2 领导干部家风建设的底色是清正廉洁}

清正廉洁不仅是领导干部为官从政要坚守的政 治底线, 也是家风建设的底色。家风是否清真廉洁是 人民群众评判领导干部是否值得信赖，能否做到永葆 初心的重要评判依据。金杯银杯不如老百姓的口碑, 老一辈革命家的清廉家风为人民群众所珍视, 世代相 传。领导干部要时刻朋紧 “廉洁” 神经线, 努力培育 清正廉洁的好家风: “清” 即两袖清风、清清白白, 领 导干部要认清 “鱼和熊掌不可兼得” 的现实, 教导家 人树立正确金钱观，同家人一起抵住金钱的诱惑，过 好金钱关; “正” 即大中至正、刚正不阿, 领导干部要 坦坦荡汤为官, 教导家人公道待人, 否落行事, 义正 言辞同不良现象作斗争; “廉”即廉洁奉公、一廉如水, 领导干部要俭以养廉, 带头厉行节约, 同家人一道弘 扬勤佮节约的美德，杜绝舌尖上的浪费行为，守住清 廉防线; “洁” 即洁身自守、志高行洁, 领导干部要洁 身自好, 培养高雅生活情趣, 同家人一道“借书增智”, 构建清爽干净的交际圈, 远离 “圈子文化”、“帮派主 义”。清正廉洁的好家风不仅是领导干部要永葆的政 治本色，更是领导干部行稳致远的强大支撑。

\section{3 领导干部家风建设的要害是严管亲属子女 和身边工作人员}

领导干部家风建设要突出聚焦重点对象。剖析高 官落马案件，会发现 “家族式腐败” 和 “衙内腐败” 多发。领导干部要在严于修身的同时筑牢 “后花园” 的篱笆，过好 “亲情关”，让家庭成为自己为官从政 的 “铠甲”, 而不是 “软胁”。为此要严慈相济, 正 常处理同家属和身边工作人员的关系。一方面，因为 领导干部政治角色的特殊性要严字当头, 讲原则。一 要严格教育、涵养正确三观, 把对党忠诚纳入家风建 设范畴中, 积极引导亲属子女爱党爱国, 努力增强政 治认同感; 二要严格管教、对特权寸步不让，决不允 许家属和身边工作人员存在特权思想，擅权干政; 三 
要严格监督、防微杜渐，谨防家属和身边工作人员被 居心匡测之人利用围猎。另一方面要严而有爱, 严慈 相济。树立正确的婚姻观，念好 “配偶经”，遵守婚姻 道德, 认真经营夫妻感情, 塑造廉内助, 谨防 “枕边 风” 乱吹; 树立正确教子观, 念好 “儿女经”, 做到爱 而不溺, 严而又度, 同时要解决好 “给子女留什么” 的问题, 决不能以权谋私, 留不义之财; 树立正确的 职位观，严管身边工作人员，时刻注意他们的思想动 态, 不能让 “耳边风” 乱吹。

\section{4. 领导干部家风建设的实践路径}

当前, 推进领导干部家风建设要运用系统思维, 综合施策, 弘扬红色家风、开展正反教育、健全党纪 党规、从严压实责任, 凝聚各方合力, 打好“组合拳”。

\section{1 弘扬红色家风，回归传承性}

习近平总书记强调 “在培育良好家风方面, 老一 辈革命家为我们作出了榜样” ${ }^{[5]}$ 。可以说红色家风是 涵养领导干部家风建设的肥沃土壤。从毛泽东立下的 亲情问题 “三原则” 到周恩来制定的 “十条家规”, 再 到朱德家风 “二三事” 等等, 这些红色家风彰显了老 一辈革命家治家管家的人政治自觉。推进领导干部家 风建设要回归传承性, 深入挖掘红色家风的丰富内涵, 传承好信仰坚定, 忠于人民、自食其力, 不搞特殊、 艰苦奋斗, 勤俭孝亲等红色价值理念; 同时要深入探 索弘扬红色家风的多种形式, 结合地域特色, 努力讲 好红色家风中的感人小故事、办好红色家风的主题展 览、拍好红色家风的宣传片, 增强红色家风的感染力 和影响力, 让红色家风落地生根。此外, 在大力号召 广大领导干部自觉向以毛泽东同志为代表的老一辈 革命家学习的同时, 持续推进红色家风进会议、进党 课、进头脑, 激发领导干部 “不想腐” 的内生动力。

\section{2 开展正反教育, 体现教育性}

推进领导干部家风建设要深化以案促改, 开展正 反典型教育, 体现教育性。一方面, 凝聚社会共识, 树立正面典型, 大力开展示党员范性教育, 积极发挥 先进典型的榜样示范作用, 努力营造 “不想腐” 的政 治氛围, 让领导干部学有榜样, 赶有目标。在向老一 辈革命家学习的同时把目光转向身边人, 善于发现并 树立身边的典型榜样。领导干部要对照先进找差距, 自觉检视自己在廉洁修身、廉洁齐家等方面存在的不 足之处, 激发见贤思齐的正能量; 另一方面, 严肃追 责问责, 通报反面案例, 大力开展党员警示教育, 发 挥反面典型的警醒震慑作用, 让领导干部知畏知止。 例如, 今年 1 月底, 电视专题片《正风反腐就在身边》 第四集《严正家风》揭示了 5 起领导干部因家风不正 而逐步腐化值落变质的典型案例, 社会反响剧烈。在 开展警示教育的时候要用好这些案例活教材, 让广大 领导干部引以为戒, 把他们的 “忓悔录” 当成自己的 “预防针”，警钟长鸣。

\section{3 健全党规党纪, 发挥制度性}

党规党纪是管党治党的重要法宝。推进领导干部 家风建设不仅要润物无声化说教于无形, 还要强化刚 性制度约束, 扎紧党规党纪的“铁笼”, 完善“不能腐” 制度体系。习近平总书记高度重视发挥党纪法规这一 “硬法” 的约束作用, 陆续出台和新修订的《中国共 产党廉洁自律准则》、《关于新形势下党内政治生活的 若干准则》、《中国共产党纪律处分条例》等多部党内 法规, 均涉及到领导干部家风建设的问题, 可谓是走 出了一条依靠制度推进领导干部家风建设的新路。这 些党规党纪对于领导干部家风建设问题提出了明确 的政治要求、纪律要求, 为其戴上了制度的“紧箍咒”。 领导干部要心中高悬党规党纪的利剑, 认真对照党规 党纪中关于家风建设的要求, 分析查找可能存在的廉 政风险点。相关部门要在认真宣传、组织领导干部学 深悟透的基础上, 抓好落实, 让铁规发力, 制度生威。

\section{4 从严压实责任，追求有效性}

推进领导干部家风建设要从严压实责任。㞘庸置 疑, 领导干部是培育自己小家清廉家风的第一负责人, 要铭记总书记的嘱托, 做到齐家有方。各级党委肩负 着抓家风建设的主体责任。一方面要将家风建设情况 纳入 “三会一课”, 积极做好领导干部的家访工作, 做 到组织关怀有温度, 在不僭越的前提下, 正面了解领 导干部在家风建设方面的情况, 出现不良势头积极进 行提醒、诫勉谈话, 正面引导。另一方面, 要严格做 好本职工作，守好责任田，紧紧围绕家产情况、婚姻 情况等, 加强领导干部个人事项报告情况的核查, 一 旦出现不实、瞒报行为, 要从严追责问责。各级纪委 (纪检组) 要积极履行监督责任, 把监督触角延伸到 “八小时之外”，弥补监督空白。

\section{5. 结论}

习近平总书记坚持问题导向，从全面从严治党的 角度问诊家风败坏的弊端, 进一步深化了家风与党风 政风的关系, 突出了领导干部家风建设的主要着力点, 同时注重凝聚各方共识、整合多方力量, 真抓实干地 推进领导干部家风建设。总之, 习近平关于领导干部 家风建设的重要论述是全面从严治党战略部署的重 要内容, 为净化党内政治生态提供了新的切入点, 具 有重大价值。广大领导干部要深刻领悟家风建设在反 腐倡廉语境下的重要性, 增强培育清正廉洁好家风的 思想认同和行动自觉, 在笃信笃行中廉洁修身, 严管 亲属子女, 以更好的家庭面貌迎接中国共产党成立 100 周年。 


\section{项目基金}

本文为天津职业大学科学研究基金项目《习近平 领导干部家风建设观研究》(20192112)、天津市哲学

\section{REFERENCES}

[1] Xi Jinping. (2015) Science as a whole to highlight the key focus for the people get more about reform.

http://www.scio.gov.cn/31773/31774/31783/Docume nt/1396388/1396388.htm.

[2] Xi Jinping.(2016)Speech at the meeting with the first national civilized family representatives.

http:/www.xinhuanet.com/politics/201612/15/c_1120127183.htm.

[3] Xi Jinping.(2021)Give full play to the leading and ensuring role of comprehensively and strictly governing the party to ensure the implementation of the goals and tasks of the 14th Five Year Plan Period.
社会科学规划项目《习近平新时代中国特色社会主义 思想对历史唯物主义的发展创新研究》(TJZXQ18-003) 的阶段性成果之一。

http://paper.people.com.cn/rmrb/html/202101/23/nw.D110000renmrb_20210123_1-01.htm.

[4] Xi Jinping.(2015)Discussion and research on measures to building a fine Party culture and a corruption-free Party,with inspection and practice the "Three Stricts and Three Steadies". http://politics.people.com.cn/n1/2015/1230/c102 4-27992581.html

[5] Xi Jinping.(2016)Speech at the Sixth Plenary Session of the 18th Central Commission for Discipline Inspection.

https://www.ccps.gov.cn/xxsxk/zyls/201812/t201 81216_125664_1.shtml. 